\title{
Political leaders of the post-1945 era
}

\begin{tabular}{|c|c|c|c|c|c|}
\hline \multicolumn{3}{|c|}{ Britain } & \multicolumn{3}{|c|}{ United States } \\
\hline Prime minister & Party & Term & President & Party & Term \\
\hline C. Attlee & Labour & $1945-51$ & F. Roosevelt & Democrat & 1945 \\
\hline W. Churchill & Conservative & $1951-55$ & H. Truman & Democrat & $1945-53$ \\
\hline A. Eden & Conservative & $1955-57$ & D. Eisenhower & Republican & $1953-61$ \\
\hline H. Macmillan & Conservative & $1957-63$ & J. Kennedy & Democrat & $1961-63$ \\
\hline A. Douglas-Home & Conservative & $1963-64$ & L. Johnson & Democrat & $1963-69$ \\
\hline H. Wilson & Labour & $1964-70$ & R. Nixon & Republican & 1969-74 \\
\hline E. Heath & Conservative & 1970-74 & G. Ford & Republican & $1974-77$ \\
\hline H. Wilson & Labour & $1974-76$ & J. Carter & Democrat & $1977-81$ \\
\hline J. Callaghan & Labour & 1976-79 & R. Reagan & Republican & $1981-89$ \\
\hline M. Thatcher & Conservative & 1979-90 & G. Bush & Republican & 1989-93 \\
\hline J. Major & Conservative & 1990-97 & W. Clinton & Democrat & 1993-2001 \\
\hline T. Blair & Labour & 1997- & G.W. Bush & Republican & $2001-$ \\
\hline
\end{tabular}


Duncan Watts - 9781847790897 Downloaded from manchesterhive.com at $\odot 4 / 26 / 2023$ ०2: $\odot 9: \odot 4 P M$ via free access 